Miradas interdisciplinarias sobre los procesos ambientales actuantes en la localidad arqueológica de Mishma (bolsón de Fiambalá, departamento Tinogasta, Catamarca) Patricia L. Ciccioli, Norma R. Ratto, Delfina Fernandez Molina, M. Elizabeth Castañeda Relaciones, 46(2), e017, julio-diciembre 2021 ISSN 1852-1479 | https://doi.org/10.24215/18521479e017 https://revistas.unlp.edu.ar/relaciones

ISSN 0325-2221 (versión impresa)

Sociedad Argentina de Antropología (SAA)

Buenos Aires I Argentina

\title{
MIRADAS INTERDISCIPLINARIAS SOBRE LOS PROCESOS AMBIENTALES ACTUANTES EN LA LOCALIDAD ARQUEOLÓGICA DE MISHMA (BOLSÓN DE FIAMBALÁ, DEPARTAMENTO TINOGASTA, CATAMARCA)
}

\author{
Patricia L. Ciccioli“, Norma R. Ratto**, \\ Delfina Fernandez Molina ${ }^{* * *}$ y M. Elizabeth Castañeda****
}

Fecha de recepción: 18 de enero de 2021

Fecha de aceptación: 6 de septiembre de 2021

\section{RESUMEN}

Se presenta un estudio interdisciplinario en la localidad arqueológica de Mishma y su entorno (bolsón de Fiambalá), enfocado en tratar de entender las variaciones ambientales durante el Holoceno tardío. Los objetivos son presentar los principales agentes formadores del paisaje físico y discutir el impacto que tuvo en las poblaciones productivas que habitaron esos espacios y su preservación en el tiempo. Se articula información de relevamientos en terreno, análisis de cartografía satelital e imágenes obtenidas por drone, datos meteorológicos y el estudio de los depósitos. El análisis permite establecer que durante la ocupación prehispánica las condiciones

\footnotetext{
* Universidad de Buenos Aires, Facultad de Ciencias Exactas y Naturales, Departamento de Geología, Instituto de Geociencias Básicas, Aplicadas y Ambientales de Buenos Aires (IGEBA, Universidad de Buenos Aires-Consejo Nacional de Investigaciones Científicas y Técnicas).E-mail: ciccioli@gl.fcen.uba.ar ** Universidad de Buenos Aires, Instituto de las Culturas (Universidad de Buenos Aires-Consejo Nacional de Investigaciones Científicas y Técnicas), Facultad de Filosofía y Letras. E-mail: nratto@ filo.uba.ar *** Universidad de Buenos Aires, Facultad de Ciencias Exactas y Naturales, Departamento de Geología, Instituto de Geociencias Básicas, Aplicadas y Ambientales de Buenos Aires (IGEBA, Universidad de Buenos Aires-Consejo Nacional de Investigaciones Científicas y Técnicas). E-mail: delfina.f.m@ gmail.com

**** Universidad de Buenos Aires, Facultad de Ciencias Exactas y Naturales, Departamento de Ciencias de la Atmósfera y los Océanos, Consejo Nacional de Investigaciones Científicas y Técnicas, Ciudad Universitaria, Pab. 2, $1^{\circ}$ piso, C.A.B.A., eliza@at.fcen.uba.ar
} 
ambientales eran distintas a las actuales en las cuales el agente eólico es uno de los principales modeladores del paisaje. El siglo XVI se interpreta como el período de cambio, previamente, la acción fluvial provocó la incisión del cauce principal del río Apocango relacionada con cambios en el nivel de base de la cuenca.

Palabras clave: geoarqueología - paisaje físico - aridez - erosión - sitios arqueológicos

\section{INTERDISCIPLINARY VIEWS ON THE ACTUATING ENVIRONMENTAL PROCESSES IN THE ARCHAEOLOGICAL LOCATION OF MISHMA (BOLSÓN DE FIAMBALÁ, DEPARTMENT TINOGASTA, CATAMARCA)}

\section{ABSTRACT}

We present an interdisciplinary study regarding the Mishma archaeological site and its surroundings (bolsón de Fiambalá) whose purpose is to understand late Holocene environmental changes. Its objective is to present the main physical landscape shaping agents and to discuss their impact on the productive populations that inhabited this area and its preservation over time. Information from field surveys, meteorological data, deposit assessment, satellite cartography and drone images analyses is articulated. Our analysis determines that during the pre-Hispanic occupation, environmental conditions were different from the present-day, in which the wind is one of the main landscape-shaping agents. We consider the sixteenth century to be the period of change; previously, fluvial action caused an incision of the main channel of the Apocango River related to changes in the basin base level.

Keywords: geoarcheology - physical landscape - aridity - erosion - archaeological sites

\section{INTRODUCCIÓN}

Los escenarios ambientales con los que interactuaron las sociedades del pasado no solo son variados a lo largo del extenso territorio de los Andes Meridionales, sino que presentan una profundidad temporal diferencial para proyectar las condiciones ambientales actuales hacia el pasado (Valero-Garcés et al. 2011; Reindel e Isla 2013; Grana et al. 2016; Morales et al. 2018; entre otros). En el oeste tinogasteño de Catamarca observamos que distintos agentes naturales interactuaron de forma tal que dieron como consecuencia que los entornos físicos actuales no tengan relación con los escenarios ambientales con los que interactuaron las sociedades productivas del pasado. En nuestro quehacer arqueológico es recurrente registrar y documentar sitios que hoy están emplazados dentro de zonas desérticas a semidesérticas (bioma de clima árido con escasas precipitaciones), pero que presentan evidencia de que fueron construidos a la vera de fuentes de agua, con la existencia de un bosque disperso y con la presencia de áreas agrícolas (Ratto et al. 2013; Orgaz et al. 2014; Andreoni et al. 2018, entre otros). Tal es el caso de la localidad arqueológica de Mishma, ubicada en la margen izquierda del zanjón de Apocango en el sector occidental del bolsón de Fiambalá en cota altitudinal entre 1.665 y 1.780 m s.n.m. (figura 1). Este espacio fue habitado desde las sociedades del primer milenio de la era (Formativo) hasta la ocupación tardía-incaica (Sempé 1976, 1984; Orgaz et al. 2007; Ratto 2013); además de haber sido un nodo logístico estratégico por conectar el valle mesotérmico de Fiambalá con la puna transicional de Chaschuil a través de antiguas rutas (Ratto et al. 2012). En este contexto, el objetivo del trabajo es, por un lado, presentar los principales agentes formadores del paisaje físico de la localidad arqueológica de Mishma y, por otro, discutir el impacto que tuvo en las poblaciones productivas que habitaron esos espacios y su preservación en el tiempo. 
Consideramos que los estudios interdisciplinarios entre arqueología y geología, que conforman el campo disciplinar de la geoarqueología, aportan a la caracterización de esos procesos ambientales definidos por intervalos que se sucedieron en el tiempo, pero que aún no cuentan con dataciones radiométricas. Su conocimiento es fundamental para comprender el impacto que tuvieron en las poblaciones del pasado, como así también en la preservación del registro material que da cuenta de sus prácticas. Para ello, articulamos información que proviene de los relevamientos en terreno, el análisis de cartografía satelital e imágenes digitales obtenidas por drone Phantom 4 Pro V2, datos meteorológicos y el estudio de los depósitos.

\section{METODOLOGÍA}

Las prospecciones y relevamientos en el área estuvieron encauzados en el marco de trabajos geoarqueológicos que consistieron en la realización de: (i) un relevamiento pedestre para georreferenciar la evidencia arqueológica y ecofactual asociada con el zanjón de Apocango e intervenida por Sempé $(1976,1984)$ décadas atrás, además de la realización de fechados radiométricos (tabla 1); (ii) un relevamiento fotogramétrico aéreo con Phantom IV Pro V2, tanto en áreas con muy buena definición arqueológica (sitio Mishma-7), como en otras localizadas en la periferia de la instalación donde solo se registran alineamientos de muro; (iii) descripción general de los perfiles naturales de distintos sectores de las barrancas del zanjón de Apocango y terrazas asociadas, y (iv) el análisis de imágenes satelitales obtenidas entre los años 2004 y 2020 provistas por Google Earth y el modelo digital de elevación obtenido a partir de las imágenes tomadas por el drone Phantom IV Pro V2, para caracterizar el entorno geográfico en donde se encuentran los sitios arqueológicos. El tratamiento digital de las imágenes georreferenciadas y el análisis topográfico fueron realizados con el programa Agisoft (versión de prueba) y Global Mapper, respectivamente.

Para la caracterización de las condiciones meteorológicas actuales se realizó el análisis de los datos obtenidos desde marzo de 2019 hasta julio de 2021 de la Estación Meteorológica Pegasus Plus instalada en la localidad de Medanitos por los autores. La estación meteorológica es de tipo inalámbrica y cuenta con sensores de temperatura de aire interna y externa, humedad de aire interna y externa, precipitación, velocidad y dirección de viento y ráfagas y presión atmosférica. Los datos son registrados en forma automática por el equipo cada 15 minutos y transmitidos a través de un módem para su consulta en línea. Además, se consultaron los datos de la estación Tinogasta del Servicio Meteorológico Nacional (Servicio Meteorológico Nacional 2015).

\section{CARACTERIZACIÓN GEOLÓGICA Y AMBIENTAL}

\section{Aspectos geológicos del zanjón de Apocango en el bolsón de Fiambalá}

El zanjón de Apocango se encuentra en la parte media del bolsón de Fiambalá, entre la localidad homónima y Saujil (figura 1). Este valle intermontano limita al este con la sierra de Fiambalá (Sierras Pampeanas Noroccidentales), al oeste con la sierra de las Planchadas (Sistema de Famatina) y al norte con la cordillera de San Buenaventura límite austral de la Puna (Rubiolo et al. 2003) (figura 1). El zanjón de Apocango se ubica en la margen sur de un abanico aluvial desarrollado en el piedemonte occidental del valle de Fiambalá, donde el río homónimo (afluente del río Fiambalá) fluye encajonado, desde el oeste hacia el este, por lo que recibe dicha denominación. La cuenca de drenaje de este abanico se ubica en la sierra de Las Planchadas. El río Apocango, efímero a intermitente por sectores, varía su patrón de meandriforme con alta sinuosidad en la parte proximal del piedemonte a entrelazado en la parte distal, donde se ubican los sitios que 
conforman la localidad arqueológica de Mishma (figura 1). Luego, segmenta otro pequeño abanico aluvial, formado a partir de las lomadas de depósitos plio-pleistocenos (Rubiolo et al. 2003), para finalmente desaguar en el centro del valle intermontano de Fiambalá. En dicho sector se forma un abanico terminal con diseño distributario de pequeña escala, $1,37 \mathrm{~km}^{2}$ de superficie (Fernandez Molina 2020), debido a que el sistema fluvial se expande y las aguas se infiltran rápidamente en los depósitos arenosos que conforman la parte de extraduna o manto eólico del campo de dunas de Medanito-Saujil (Deri y Ciccioli 2018).

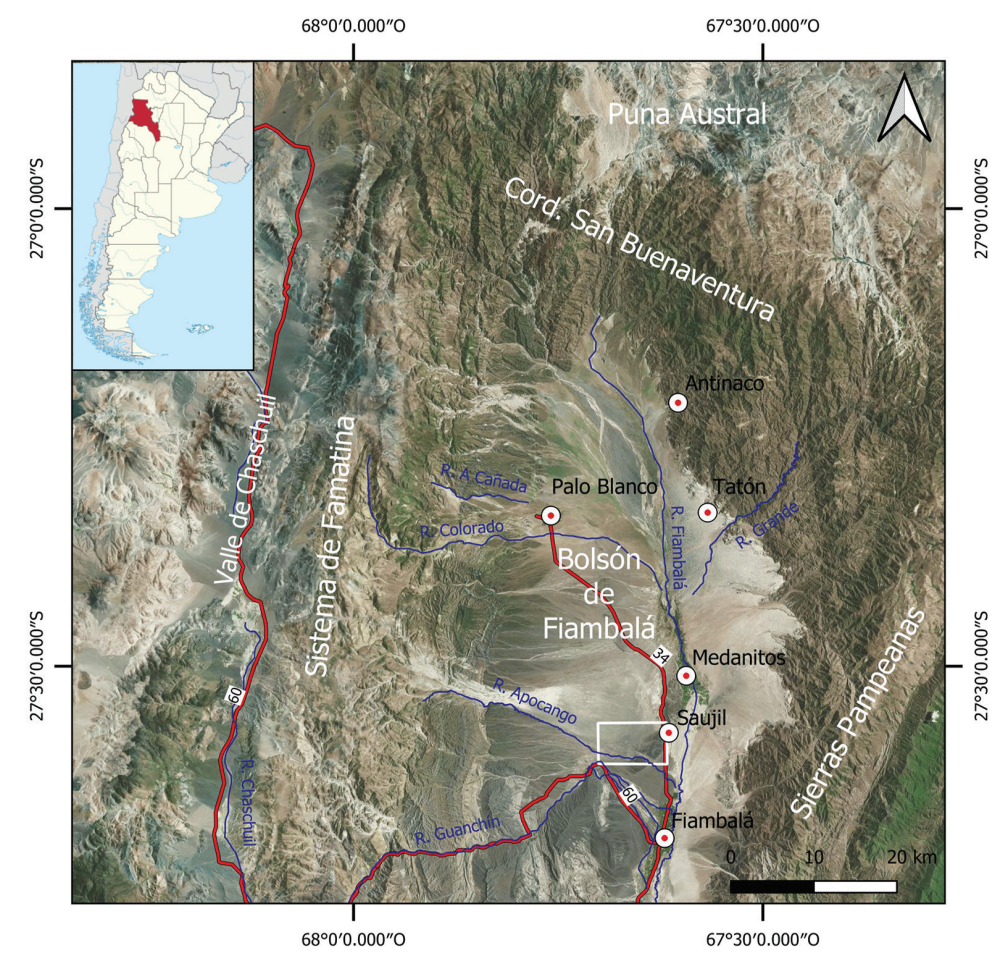

Figura 1. Mapa de ubicación del área de estudio. El recuadro indica la localidad arqueológica de Mishma (departamento Tinogasta, Catamarca)

\section{Aspectos ambientales del bolsón de Fiambalá y su impacto en las poblaciones}

El bolsón de Fiambalá se localiza dentro de la faja climáticamente seca denominada Diagonal Árida (Bruniard 1982) que se extiende a lo largo de los Andes, desde el Ecuador hasta la Patagonia. A la latitud del área de estudio, el alto orográfico que representa la cordillera de los Andes produce un efecto de barrera de los vientos occidentales húmedos provenientes del océano Pacífico. Además, el área se encuentra en una zona de transición entre dichos vientos occidentales húmedos y el sistema monzónico tropical (Garleff et al. 1992; Garreaud et al. 2009). Por este motivo, en la región las precipitaciones no superan los $100 \mathrm{~mm}$ /año promedio, según los datos registrados desde 1985-2015 en la estación meteorológica de Tinogasta (S28 04' O67 $^{\circ} 34^{\prime} ; 1.201$ m s.n.m.), cabecera del departamento del área de estudio (Servicio Meteorológico Nacional 2015). Las precipitaciones se concentran en el período estival y cuando ocurren se caracterizan por su carácter torrencial. Los vientos tienen una dirección preferencial desde el SSO, y alcanzan su velocidad máxima promedio de $13,7 \mathrm{~km} / \mathrm{h}$ en $\operatorname{los}$ 
meses de septiembre y octubre, aunque son frecuentes ráfagas de entre 40 y $100 \mathrm{~km} / \mathrm{h}$ (Servicio Meteorológico Nacional 2015; Viera 1982).

Para evaluar mejor las condiciones climáticas en regiones con topografía compleja como el área de estudio, la actual resolución espacial de los modelos de circulación general es pobre y, por lo tanto, son indispensables las observaciones de temperatura, lluvia, nieve y viento registradas por estaciones meteorológicas in situ. La serie de datos, desde marzo 2019 a julio de 2021, obtenidos a partir de la estación meteorológica Pegasus Plus en la localidad de Medanitos indican que las temperaturas medias diarias (figura 2a), estimadas como el promedio de los valores de temperatura del aire registradas cada 15 minutos durante un día y los valores medios, oscilaron entre $1,2^{\circ}$ y $29,7^{\circ}$ $\mathrm{C}$, con valores extremos de $43,1^{\circ} \mathrm{C}$ y $-9,4^{\circ} \mathrm{C}$. En general, durante los inviernos los registros de las temperaturas mínimas absolutas oscilaron alrededor de $0^{\circ} \mathrm{C}$. A escala mensual, las temperaturas medias fueron entre $26,2^{\circ} \mathrm{C}$ y $8,0^{\circ} \mathrm{C}$, enero de 2020 y junio de 2021 , respectivamente (figura $2 \mathrm{~b}$ ).

La humedad relativa varió significativamente (figura $2 b$ ), durante todo el período de estudio con una mediana de $41 \%$. Este valor es mayor al registrado en la zona cordillerana de Las Grutas (mediana del 11\%), al oeste del área de estudio, durante el 2010 y 2012 (Castañeda y Ratto 2009).

Por su parte, la marcha de la precipitación media mensual registrada (figura 2c) denota una estación seca (mayo a septiembre) y una estación húmeda (octubre a abril), aunque los valores medios son escasos. Entre los valores acumulados mensuales para el período de registro, se observa que abril de 2019 es el mes que más llovió (32 mm, figura 2d) y, en particular, la precipitación se registró un solo día, el 5 de abril (32 mm). Mientras que la dirección del viento más frecuente es del sudoeste y en segundo orden del oeste, con mayor variabilidad en los meses de junio y julio, con velocidades de hasta $50 \mathrm{~km} / \mathrm{h}$ (figura $2 \mathrm{e}$ ).

Estas condiciones climáticas, características del Noroeste argentino, han variado durante el Holoceno tardío cuando se registran periodos de mayor aridez y periodos de mayor humedad (Garleff et al. 1992; Valero-Garcés et al. 2003, 2011; Prieto et al. 1998, Prieto y Herrera 2009, entre otros).

Bajo estas condiciones, los episodios de sequía, los torrentes de barro (o "volcanes") y las erupciones volcánicas, dependiendo de su duración e intensidad, pueden ocasionar profundas alteraciones en el ecosistema y en la configuración del entorno físico, por lo que generan un impacto negativo en el desarrollo de las actividades socioeconómicas en las poblaciones que habitan y habitaron las áreas afectadas. Actualmente, el amplio bolsón de Fiambalá, incluyendo el zanjón de Apocango, presenta, como se describió previamente, condiciones ambientales áridas a semiáridas, por lo que resulta un área muy sensible a variaciones en las precipitaciones. Gran parte de los depósitos más superficiales son de origen eólico y, en menor medida, fluvio-aluviales cubiertos en sectores por suelos pobremente desarrollados. Por lo tanto, ante pérdidas de la cubierta vegetal por causas antrópicas y naturales, resultan muy lábiles a ser retrabajados (Vervoorst 1951; Rojas 2013).

En general, la región de Fiambalá tuvo un papel diferencial en la historia del habitar de las sociedades productivas del primer y segundo milenio de la era cristiana, aproximadamente los últimos 2000 años, que en gran parte se desarrolló al compás de los eventos ambientales, algunos de naturaleza catastrófica relacionados directa o indirectamente con la masa de material no consolidado depositado por las erupciones volcánicas y/o por los torrentes ("volcanes") de barro y/o pómez (Ratto et al. 2013; Fernández-Turiel et al. 2019; Ratto et al. 2019b).

Valero-Garcés y colaboradores (2011) ubicaron temporalmente la transición regional entre una dinámica fluvial de acumulación y la actual dominada por el encajamiento fluvial y la erosión mediante la datación de niveles de turba en la barranca del río Chaschuil -a 3.000 m s.n.m.- que arrojó una edad de $1828 \pm 38$ AP (AA60924, polen, 128-361 años de la era cristiana, calibrado OxCal 4.4, 2 sigmas, curva SHCal20, Hogg et al. 2020). Sobre esta base, consideran que los procesos erosivos en la región comenzaron en los primeros siglos de la era cristiana, por lo que afectaron a las poblaciones del primer milenio, tardía e inca, pero acuerdan que esos procesos se 
potenciaron con el abandono del área producto de la conquista española, tal como previamente fue señalado por Garleff et al. (1992).

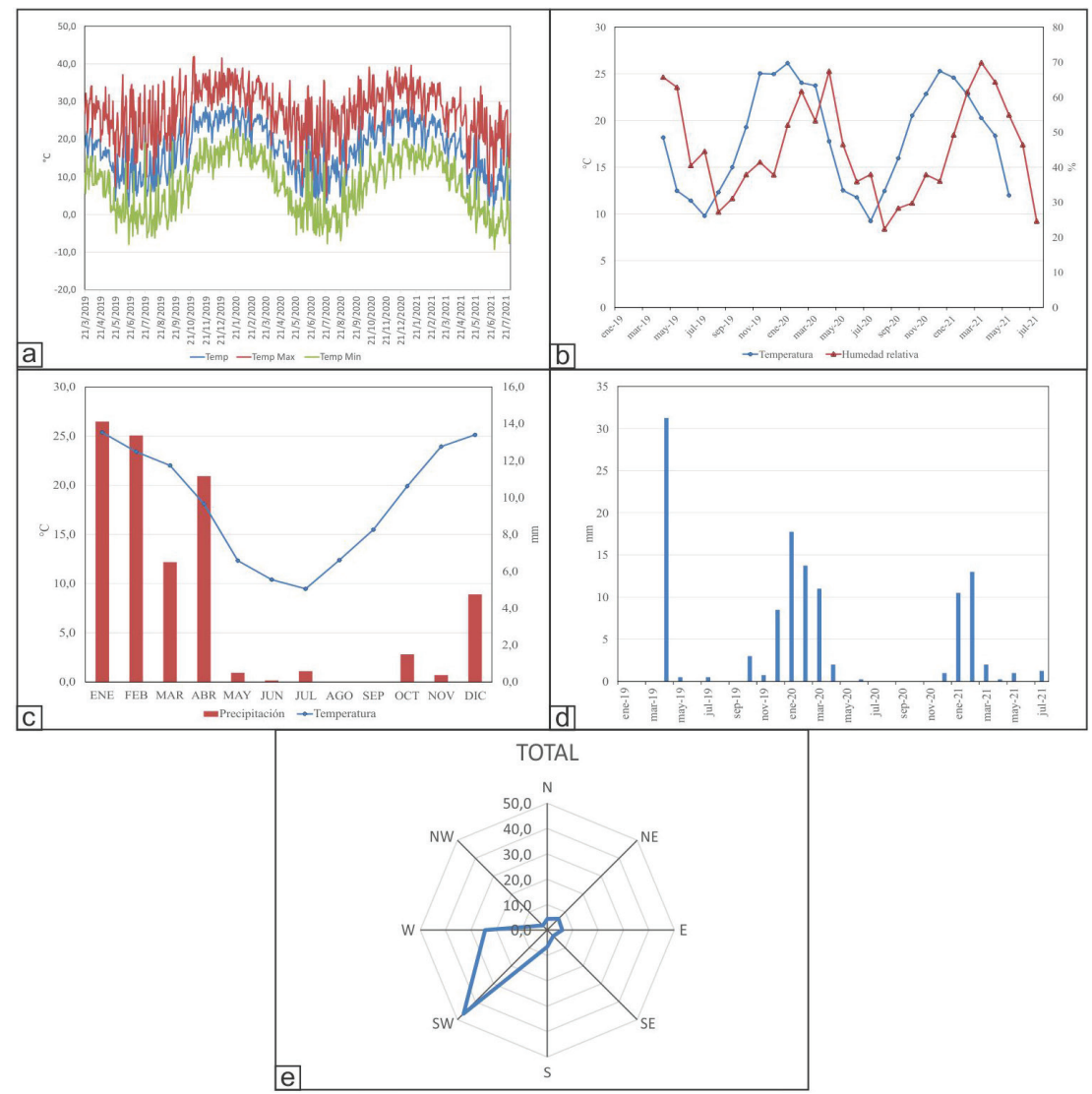

Figura 2. Datos meteorológicos obtenidos a partir de la estación Pegasus Plus desde marzo 2019-julio 2021: (a) temperatura media, máxima y mínima mensual; (b) temperatura media y humedad relativa;

(c) temperatura mensual media y precipitación mensual; (d) valores de precipitaciones mensuales registradas; y (e) direcciones del viento

Situaciones similares de encajonamiento se registraron en los ríos Agua de la Cañada, Colorado y Grande, lo que estaría indicando un fenómeno de alcance regional (figura 1). Un ejemplo, son los sitios Tatón I y II, de función residencial y su área agrícola asociada, respectivamente (Orgaz et al. 2014). El primero está emplazado en un cono aluvional que fue cortado por un brazo del río Grande, afluente del río Abaucán. Hoy, el paleocauce está cubierto por dunas y mantos eólicos que caracterizan el paisaje físico moderno (Valero-Garcés y Ratto 2005).

Alrededor del año 1000 d.C. hemos registrado el abandono de aldeas emplazadas en el fondo de valle (Ratto et al. 2019a), lo que también está acompañado de ausencia de cualquier otra señal arqueológica. Las causas pueden deberse a múltiples factores. Sin embargo, en clave regional, consideramos que ese espacio presentaba condiciones de inhabitabilidad debido a una inestabilidad ambiental generada por torrentes y flujos que movilizaron grandes volúmenes de material pumíceo no consolidado en superficie, producto de erupciones volcánicas previas (Fernández-Turiel et al. 2019; Ratto et al. 2019b). Esta situación se revierte a mediados del siglo XIII, y hacia fines del siglo XIV se produce el repoblamiento de la región por el Inca y los pueblos movilizados en 
el marco de sus estrategias expansivas de dominación (Ratto 2013; Orgaz y Ratto 2015, entre otros). Posteriormente, la llegada del español conlleva modificaciones en las formas de vida y de explotación del territorio, principalmente por deforestación y sobrepastoreo, produciendo efectos en el entorno ambiental y probablemente favoreciendo la ocurrencia de eventos naturales más severos (Cuello 1992; Rojas 2013). Para la comprensión de este contexto dinámico, donde interactúan agentes naturales y antrópicos, es relevante articular las miradas de las humanidades y de las ciencias de la tierra para así comprender la evolución de los procesos y la interacción entre las variables del entorno geográfico y cultural.

\section{ANTECEDENTES DE LA LOCALIDAD ARQUEOLÓGICA DE MISHMA}

Esta localidad arqueológica fue relevada e intervenida por María Carlota Sempé a fines de la década de 1960 (Sempé 1976, 1984). Al respecto, los sitios $\mathrm{N}^{\circ} 1$ a $\mathrm{N}^{\circ} 6$, muy erosionados, estaban compuestos por alineaciones de piedras y acumulaciones de arcillas que formaban pequeñas lomadas y estaban asociados con materiales diversos (artefactos de molienda, fragmentos de alfarería formativos, tardío e inca, y metal). En estos sitios realizó prospecciones, recolecciones de superficie $\left(\mathrm{N}^{\circ} 3,4,5\right.$ y 6$)$ y excavación en trincheras $\left(\mathrm{N}^{\circ} 1\right.$ y 2). Dentro del espacio del zanjón de Apocango destaca el sitio Mishma-7 por su mejor preservación (figura 3a). Está construido con la técnica de pirca con muros simples y dobles y presenta dos grandes núcleos arquitectónicos conformados por varios recintos, encerrados por un muro perimetral (Sempé 1984:figura 3a, b). La investigadora consideró que esta localidad arqueológica tenía como entorno un bosque de algarrobo emplazado a lo largo del zanjón de Apocango, del cual hoy queda solo un remanente.

Esta localidad da cuenta del desarrollo cultural de la etapa agroalfarera del área valliserrana con mejor preservación de las ocupaciones correspondientes a los períodos Tardío e Incaico, sobre las del Temprano y del Medio. Sempé (1984) destaca la existencia de un fenómeno de desecamiento paulatino, ya advertido por Turner (1967), pero de carácter muy lento que no implica la existencia de un cambio climático drástico en el pasado más reciente, hace unos 500 a 1000 años atrás.

En el marco del Proyecto Arqueológico Chaschuil-Abaucán (PACh-A) se realizaron nuevas prospecciones, pero los sitios $\mathrm{N}^{\circ} 1$ al $\mathrm{N}^{\circ} 6$, luego de 40 años, se encontraban en peor estado de preservación con respecto al documentado por Sempé $(1976,1984)$. En el caso del $N^{\circ} 7$ no se realizaron nuevas excavaciones por no poder identificarse los espacios previamente intervenidos. Sin embargo, la evidencia superficial, especialmente la alfarería, daba cuenta de la existencia de distintos estilos cerámicos característicos de los períodos culturales mencionados por Sempé $(1976,1984)$. Además, se pudo tener acceso a la colección formada por la colega (cerámica, metales y macrorrestos vegetales), analizada en otros trabajos, pero que principalmente permitió la obtención de fechados radiométricos que confirman la ocupación de este espacio en distintos momentos de la historia regional, tanto por las sociedades aldeanas del primer milenio como la estatal incaica (tabla 1).

De la localidad de Mishma también proviene la colección particular de Lorenzo Castro, poblador de Fiambalá, en la que destacan las piezas líticas grabadas (morteros, conanas, cutanas y hachas), un topu de metal posiblemente incaico y piezas cerámicas abiertas y cerradas que, por sus características morfológicas y visuales corresponden tanto al primero como al segundo milenio de la era cristiana (estilos Aguada, Belén y Sanagasta) (Ratto y Basile 2020). Estos espacios fueron afectados por intensos procesos erosivos y de acreción y/o agradación que produjeron modificaciones de la estratigrafía, generación de palimpsestos y disminución en la integridad de los restos materiales. 
Relaciones de la Sociedad Argentina de Antropología 46 (2), julio-diciembre 2021: 483-501

Tabla 1. Fechados radiométricos de la localidad arqueológica de Mishma

\begin{tabular}{|c|c|c|c|c|}
\hline Sitio & $\begin{array}{c}\text { Sigla } \\
\text { Laboratorio }\end{array}$ & Detalle de muestra y proveniencia & $\begin{array}{l}\text { Datación } \\
\text { radiométrica } \\
\text { (años AP) }\end{array}$ & $\begin{array}{c}\text { Años } \\
\text { Calendáricos } \\
\text { (Año Domini)* }\end{array}$ \\
\hline 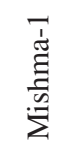 & LP- 2638 & $\begin{array}{l}\text { Intervención C. Sempé, 1971. Carbón de } \\
\text { fogón recuperado en profundidad de 0-15 cm }\end{array}$ & $1470 \pm 60$ & $578-668$ \\
\hline 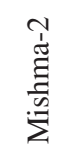 & LP- 2647 & $\begin{array}{l}\text { Intervención C. Sempé, 1971. Trinchera } 1 . \\
\text { Carbón de fogón de cavidad del fogón a } 40 \\
\text { cm de profundidad. }\end{array}$ & $500 \pm 50$ & $1410-1462$ \\
\hline \multirow{3}{*}{ 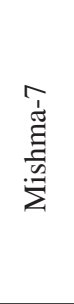 } & AA69979 & $\begin{array}{l}\text { Intervención C. Sempé, 1971. Carbón de } \\
\text { fogón, piso de ocupación, Estructura A }\end{array}$ & $514 \pm 35$ & $1423-1451$ \\
\hline & YU-1543 & $\begin{array}{l}\text { Intervención C. Sempé, 1971. Núcleo IV, } \\
\text { Hab. I, fogón sur, vaina de algarroba }\end{array}$ & $457 \pm 21$ & $1446-1483$ \\
\hline & MTC-15592 & $\begin{array}{l}\text { Intervención C. Sempé, 1971. Núcleo } \\
\text { habitacional V - Habitación A Central, marlo } \\
\text { maíz }\end{array}$ & $297 \pm 26$ & $1518-1666$ \\
\hline
\end{tabular}

* Referencia: Programa OxCal 4.4, Curva calibración SHCal20 (Hogg et al. 2020), 1 sigma https://c14.arch.ox.ac.uk/oxcal.html

\section{NUEVOS RELEVAMIENTOS EN LA LOCALIDAD ARQUEOLÓGICA DE MISHMA}

El zanjón de Apocango actualmente se caracteriza por presentar un ambiente desértico, sin provisión de agua en ningún momento del año (figura 3) salvo durante eventos extraordinarios de precipitaciones torrenciales o intensas. De esto dan cuenta el relevamiento fotogramétrico de los $200 \mathrm{~m}^{2}$ del sitio Mishma-7 y su entorno inmediato (figura 3a-b), como también los alineamientos de rocas y muros dobles localizados en su periferia, hoy en muy mal estado de preservación, pero que dan idea de que en el pasado fue un área agrícola emplazada a $800 \mathrm{~m}$ al este de la instalación (figura 3c). Además, a la vera del zanjón se registraron seis "tocones" de algarrobo que, puestos en contexto, daban una mayor cobertura arbórea. Son evidentes los cambios ambientales, especialmente hidrológicos, que tuvieron lugar en el área y afectaron las instalaciones del pasado.

Las observaciones de campo y el análisis detallado de las imágenes satelitales, entre 2004 y 2020, permitieron reconocer un abanico aluvial de escala mediana $\left(\sim 120 \mathrm{~km}^{2}\right)$ en el piedemonte occidental con tres sectores diferenciados: proximal, medio y distal (figura 4a). La cuenca de drenaje se ubica en la sierra de Las Planchadas y el abanico presenta un diseño distributario caracterizándose por el aumento en la cantidad de canales, actualmente efímeros, desde la parte proximal a la distal. Uno de estos canales principales, en el margen sur de dicho abanico, corresponde al río Apocango que presenta agua en forma permanente a intermitente en un solo sector en la parte proximal del piedemonte cercano al ápice del abanico (desde los S27³2'28.48' O6749'44.99"

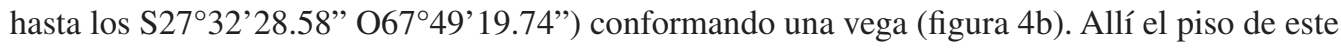
canal se encuentra entre 15 a $20 \mathrm{~m}$ por debajo del nivel superficial del abanico. Aguas abajo el río se insume completamente en los depósitos arenosos que conforman el piedemonte. Cabe mencionar que en la localidad de Saujil el agua surge como un manantial (pozos surgentes) resultado 
de las aguas subterráneas que fluyen por debajo del piedemonte occidental y emergen allí en la zona más baja del valle probablemente debido a un control estructural.

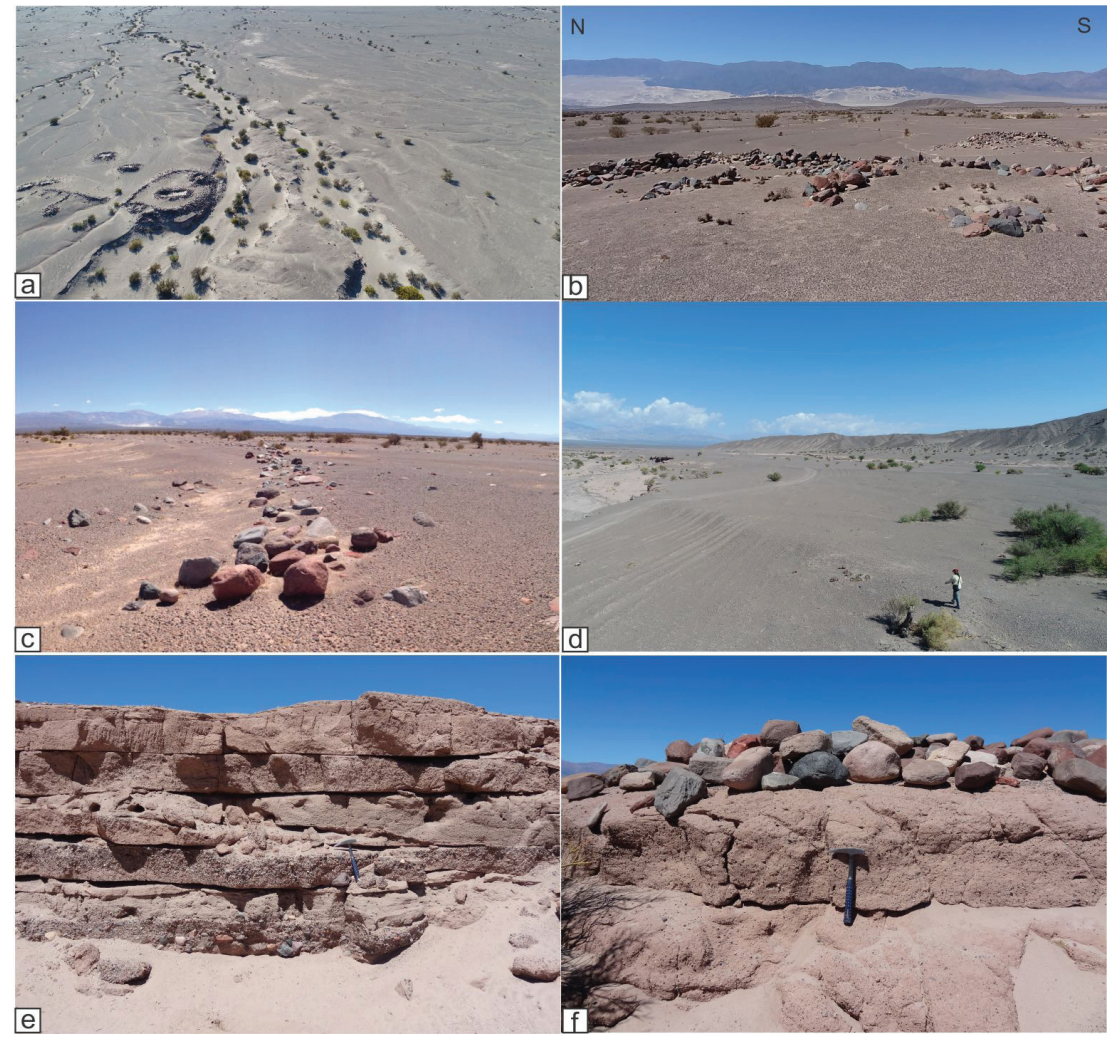

Figura 3. (a) Vista aérea del sitio Mishma-7 y entorno desértico (Phantom IV Pro V2); (b) vista desde el oeste de un sector del sitio Mishma-7 y la parte angosta del zanjón de Apocango en el fondo;

(c) alineamientos de rocas en la periferia este del sitio Mishma-7; (d) megaóndulas transversales o transverse aeolian ridge en el zanjón de Apocango; (e) perfil natural de la barranca del río a la altura del sitio Mishma-7; y (f) rocas del sitio Mishma-7 sobre los depósitos gravo-arenosos del río

En los sectores de cabecera y parte proximal del abanico se reconoce un sistema de dunas que van variando en la morfología de barjanes a transversales con crestas rectas con dirección principal de las crestas NE-SO (figura 4 b-d). Estas dunas descienden, desde el oeste al este, por la suave pendiente del abanico (pendiente promedio $=0,039 \mathrm{~m} / \mathrm{m}$ o $39 \%$ ). En la parte media del abanico estas geoformas eólicas pasan a protodunas y mesoformas de acreción fijas, principalmente sombras de arena y zibars, y microformas (ondulas eólicas) (figura 5a). Es notable la importante cobertura de arena en este sector (agradación) que conforma un manto eólico donde las geoformas presentan una dirección de transporte dominante hacia el norte (figura 5a). Es probable que el aporte de estos sedimentos sea desde el oeste al igual que en el abanico proximal, pero se requiere de la realización de estudios composicionales para establecer con precisión las fuentes de aporte.

En la parte distal del abanico estas geoformas arenosas eólicas disminuyen notablemente (figura 5b-c), predominando la deflación eólica sobre la amplia superficie que conforman las áreas de intercanal. Estas extensas áreas se desarrollan entre canales fluviales someros efímeros, reconociéndose escasas mesoformas fijas de acreción aisladas con dirección de transporte hacia el E-SE y microformas (ondulas eólicas) o pequeñas acumulaciones de arena tanto en el piso 


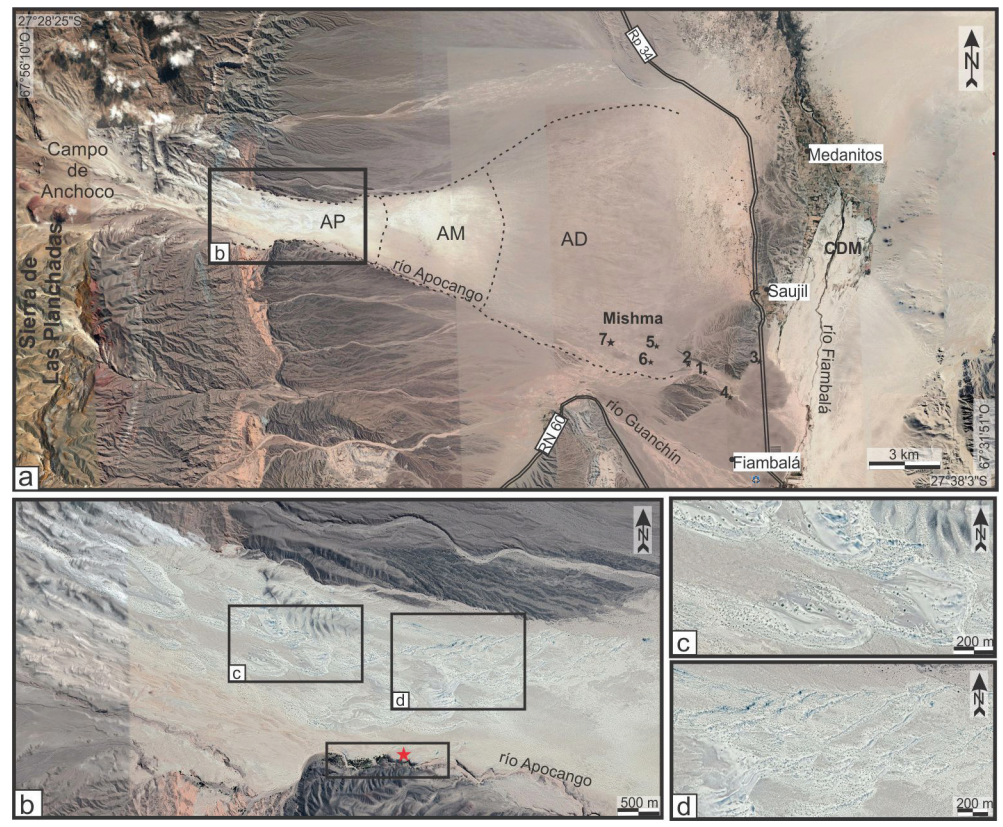

Figura 4. Imágenes satelitales provistas por Google Earth del área de estudio, (a) abanico desarrollado en el piedemonte occidental del bolsón de Fiambalá con sus tres sectores marcados: proximal (AP), medio (AM) y distal (AD) y ubicación relativa de los sitios Mishma (sensu Sempé 1984); (b) sector proximal donde se observan dunas eólicas y el sector con agua permanente en el río Apocango (estrella); (c) detalle de las dunas barjanes, (d) dunas de crestas rectas con dirección de cresta principal NE-SO

como en los márgenes de los canales al reparo del viento (figura 5b-c). En el sector más distal y hacia el sur es donde empiezan a reconocerse geoformas particulares que pueden interpretarse como megaóndulas de arena cubiertas por gravas o transversal aeolian ridges (TAR, Fernandez Molina 2020, figura 3d). Estas geoformas se encuentran mejor desarrolladas en la parte angosta del zanjón donde se encuentra limitado por los depósitos plioceno-pleistocenos (Rubiolo et al. 2003) que afloran conformando dos pequeñas lomadas (figura 3b). Aquí la deflación es uno de los procesos predominantes, lo que favoreció el desarrollo de un pavimento del desierto formado por una cobertura superficial de gravas finas a medianas asociadas a hoyos de deflación. En esta parte más distal del abanico es donde se ubican los distintos sitios de superficie de la localidad arqueológica de Mishma (figura 5c). Por ejemplo, en el sitio Mishma-7 (figura 6) el cauce del río se encuentra entre 3 a 3,5 m por debajo del nivel de la superficie actual del terreno. Dichos valores fueron medidos en el campo como también a partir del modelo digital de elevación obtenido por fotogrametría usando el programa Global Mapper (figura 6b, c).

Los perfiles naturales de las márgenes de los canales fluviales presentan $2 \mathrm{~m}$ de espesor (figura 7), tanto en el sector del sitio Mishma-7 (P1 en figura 7) como en la parte más angosta del zanjón (P2 en figura 7), los que están integrados por depósitos gravo-arenosos en bancos de geometría tabular a mantiforme de $20 \mathrm{~cm}$ de espesor en promedio (figura 3e, f). Predominan las gravas finas a medianas (guijas) y las arenas gruesas a medianas con estratificación horizontal, estratificación entrecruzada de bajo ángulo y estructura maciza, siendo menos frecuente la estratificación entrecruzada tabular planar y la laminación ondulítica. Se reconocen escasos y delgados niveles, de hasta $10 \mathrm{~cm}$, de arenas finas con laminación horizontal con gradación inversa de intralámina. Dichos perfiles han sido estudiados en detalle por Fernandez Molina (2020) quien interpretó que corresponden a una alternancia de depósitos mantiformes a pobremente canalizados correspondientes 


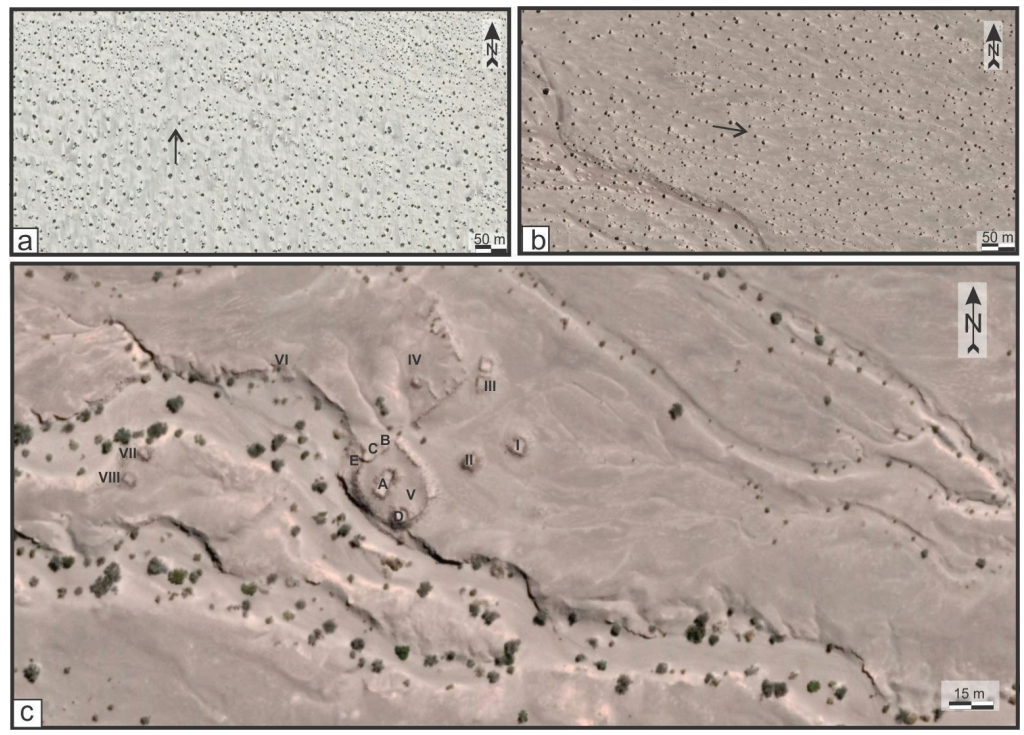

Figura 5. Imágenes satelitales provistas por Google Earth del área de estudio: (a) sector medio del abanico con predominio de mesoformas arenosas fijas principalmente sombras de arena con dirección de migración principal al N (flecha), (b) sector distal mostrando una notable disminución de las geoformas eólicas arenosas con dirección de transporte al E (flecha); (c) sitio Mishma-7 con la numeración de los distintos recintos según Sempé (1976) en el sector más distal del piedemonte

a flujos fluidos de alta energía (alto régimen de flujo) y flujos hiperconcentrados no cohesivos, con alta relación sedimento/agua (entre un 50 y 70\%, Costa 1988) y poca a nula participación de fango (no cohesivo). A su vez, la presencia de arenas finas con laminación inversa de intralámina evidencian la interacción eólica-fluvial producto de la migración de ondulas eólicas. Ningún tipo de material arqueológico se recuperó dentro de los perfiles naturales descriptos y muestreados, debido a que la localidad presenta sitios con visibilidad en superficie, pero la caracterización de aquellos es fundamental para modelar las condiciones del sistema fluvial previo y/o durante la ocupación del sitio.

\section{DISCUSIÓN}

Los recientes relevamientos geológicos y arqueológicos de la localidad de Mishma conforman nueva evidencia para dar cuenta de que el asentamiento humano prehispánico en la región interactuó con un paisaje físico diferente al actual, especialmente porque los ríos no presentaban el nivel de incisión actual, ni tampoco existía un paisaje desértico de dunas y manto eólico (Valero-Garcés y Ratto 2005; Valero-Garcés et al. 2011; Ratto et al. 2013). Los fechados radiométricos dan cuenta del habitar de este espacio tanto en tiempos prehispánicos, siglos VI y XVI, tal como daban cuenta los estilos cerámicos recuperados en superficie y excavación, como en momentos hispano-indígenas (tabla 1).

La ubicación de los sitios de la localidad arqueológica de Mishma es estratégica ya que constituye un conector entre el valle mesotérmico y los pisos puneños y altoandinos. En el caso de Mishma-7 debió proveer agua y forraje ya que el asentamiento incaico, con presencia de población local, funcionó como un punto de parada, "tambo" o "posta", de residencia permanente alternada, emplazado en la ruta que comunica el sector sur del valle de Fiambalá con el sector 

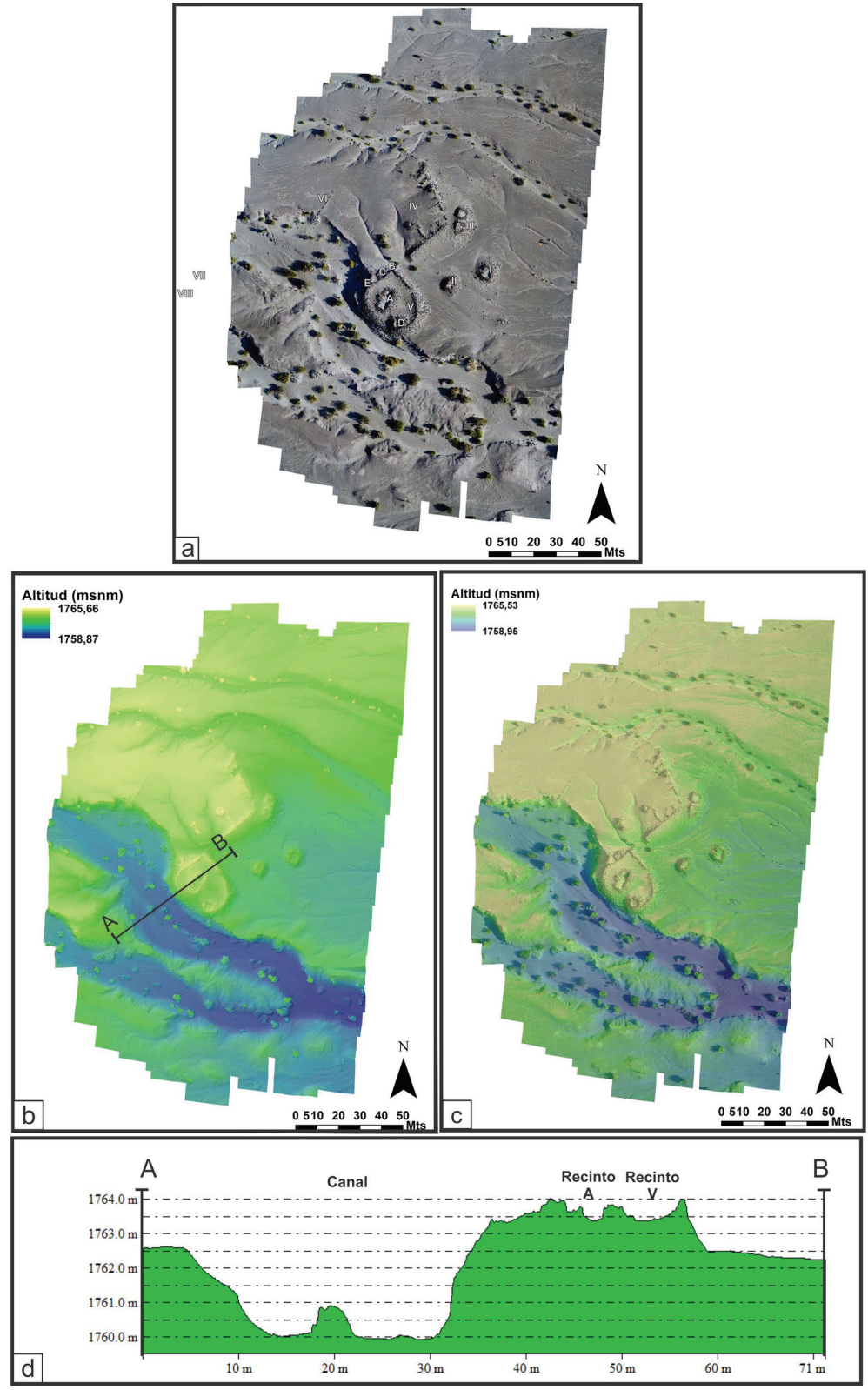

Figura 6. Imágenes digitales obtenidas con Phantom IV Pro V2, (a) ortomosaico del sitio Mishma-7 con la numeración de los recintos según Sempé (1976) en el sector más distal del piedemonte, (b) modelo digital de elevación (DEM), (c) DEM con el ortomosaico sobreimpuesto, (d) perfil topográfico obtenido a partir del DEM (A-B en la figura b) 


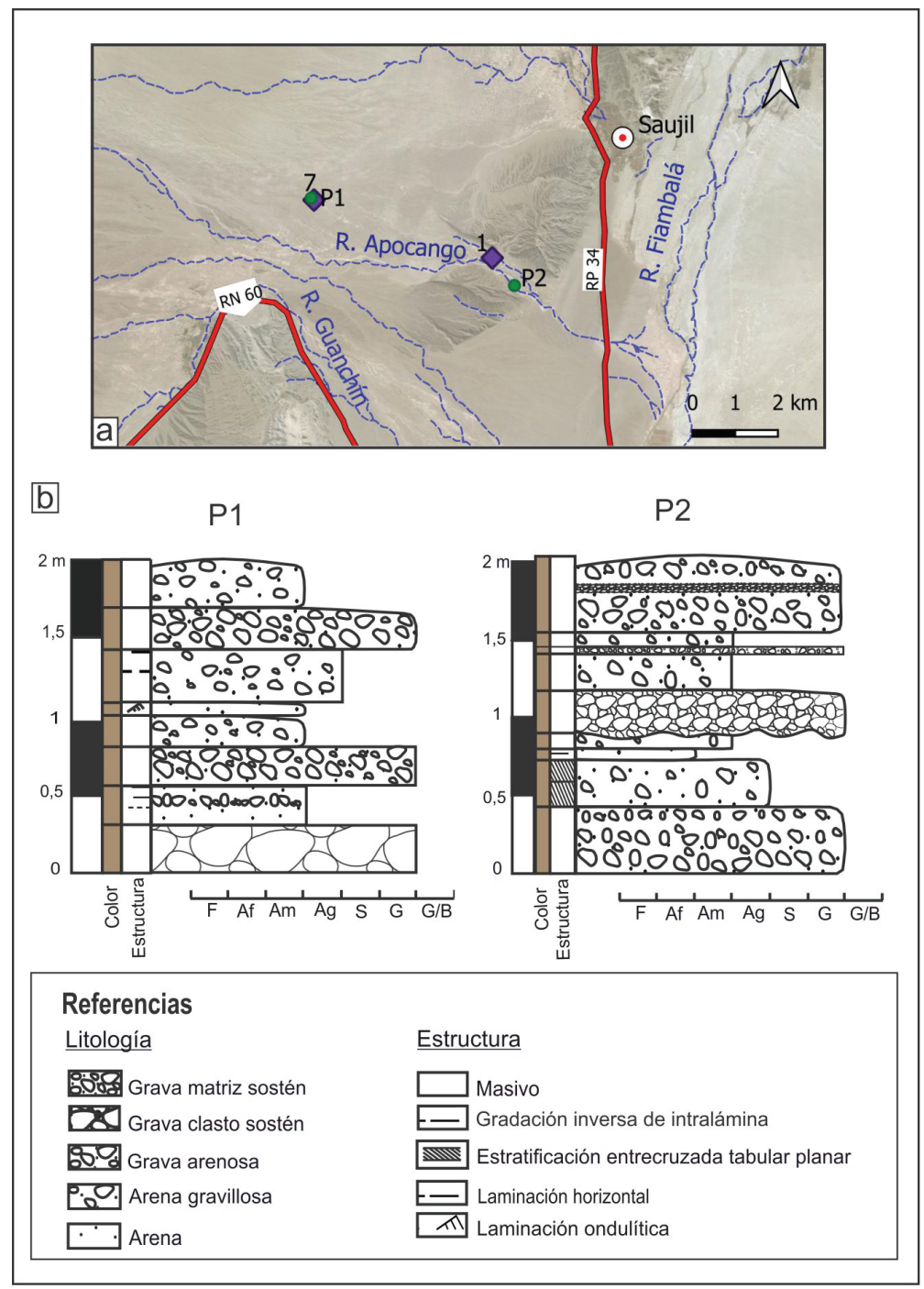

Figura 7. (a) Mapa de ubicación de los perfiles sedimentológico-estratigráficos descriptos en los márgenes de los canales fluvial, (b) perfiles P1 en las cercanías de Mishma-7 y P2 en la angostura del zanjón cerca del sitio Mishma-1

norte, cruzando la pampa de Fiambalá, y hacia el oeste con las tierras altas de la puna transicional de Chaschuil para comunicar con las tierras trasandinas (Sempé 1984; Ratto et al. 2012). Por lo tanto, consideramos que entre los años 1400 y 1500 de la era cristiana (tabla 1) estos entornos presentaban condiciones apropiadas para asegurar la transitabilidad de personas y animales, como así también la residencia alternada. Prueba de ello es la información que contiene la Colección de Folklore, producto de la Encuesta Nacional de Magisterio realizada en 1921 (Ferreira 2005). Al respecto, destacamos el relato de Don Bartolo Funes, 92 años, quien menciona que pasaba por el sitio Mishma-7 en su juventud, a mediados siglo XIX, en viaje a la cordillera para cruzar a Chile y realizó excavaciones en el sitio que ya estaba inmerso dentro de un espacio desértico (Carpeta 19, p.15). 
Varias pueden ser las causas que hayan generado un cambio en el perfil de equilibrio de los sistemas fluviales que produjeron las modificaciones del paisaje físico. Una de las hipótesis plausibles es que los cursos del agua fueron endicados aguas arriba, en el sector proximal del piedemonte, debido a la importante acumulación de sedimentos, principalmente de origen volcánico, transportados por el viento (dunas y mesoformas eólicas) como ha sido descripto en la sección anterior. Estos endicamientos, asociados probablemente a una disminución en el caudal del río, generaron que los procesos eólicos de acreción y/o agradación en la parte proximal a media del abanico y los de deflación en el sector distal del piedemonte primaran sobre el agente fluvial en esos espacios. La disminución en el caudal de los ríos del valle ha sido registrada en datos históricos por el Servicio Nacional de Información Hídrica (figura 8) desde 1919-1956 y los valores actuales (2016-2020). El registro muestra que el caudal promedio del río Abaucán en la estación Tinogasta a principios del siglo XX (1919-1920) era de 3,5 $\mathrm{m}^{3} / \mathrm{seg}$, el cual fue disminuyendo hasta alcanzar actualmente valores de $1,18 \mathrm{~m}^{3} / \mathrm{seg}$ (promedio entre 2016-2020), con valores menores a $0,6 \mathrm{~m}^{3} / \mathrm{seg}$ en algunos años. Sin embargo, durante los períodos de lluvias extraordinarias -cuando los ríos aumentan su caudal (por ejemplo, el río Abaucán registra valores de caudal de hasta $21,4 \mathrm{~m}^{3} / \mathrm{seg}$ en enero de 1925 , Servicio Nacional de Información Hídrica 2021) - la acción fluvial generó erosiones de distinta jerarquía que fueron de mayor orden en la parte proximal del piedemonte donde se encuentra el canal principal del río Apocango (incisión del orden de decenas de metros (10-20 m) que formaron el denominado "zanjón") y menores en la parte distal (3-3,5 m). Dichas erosiones fueron producidas por el sistema fluvial para poder ajustar su perfil de equilibrio al nivel de base actual de la cuenca. Cabe mencionar que procesos neotectónicos (levantamiento del frente montañoso en la zona proximal como de las lomadas de la parte distal) deben ser también considerados como probables generadores de alteraciones del perfil de equilibrio de los sistemas fluviales. Estudios detallados de este tipo deben ser realizados para poder entender mejor la evolución del paisaje físico durante el Holoceno tardío.

Estos procesos naturales pueden haber sido intensificados por otros de naturaleza sociocultural, que en conjunto provocaron una importante modificación del paisaje físico desde la ocupación de los sitios en los siglos VI al XVI hasta las condiciones actuales. Por un lado, la desestructuración social producto de la conquista española y la implementación del sistema de encomiendas que provocó un nuevo despoblamiento de estas tierras (Ratto y Boixadós 2012). La falta de mantenimiento de los campos agrícolas y obras relacionadas (acequias, canales) fue un disparador para intensificar los procesos erosivos, en gran parte debido a la mayor disponibilidad de sedimento en superficie para ser transportado por el viento. A ello se sumó la deforestación, principalmente por la tala intensa de los bosques nativos de algarrobo relacionada con actividades extractivistas como la minería y el ferrocarril durante los siglos XIX-XX (Rojas 2013, Rojas et al. 2014). La actividad minera, desarrollada principalmente en Capillitas y Famatina (entre 1850 y 1914), fue la primera que motorizó el desmonte intensivo de gran parte de los bosques (Bazán 1996; Argerich 2003 a, b, entre otros). Posteriormente, el ferrocarril intensificó el desmonte utilizando los forestales tanto para su construcción como para medios de transporte (leña, carbón y postes) hacia las regiones cuyanas y pampeanas en plena expansión comercial y de desarrollo económico (Rojas 2013; Rojas et al. 2014).

Por lo dicho, podemos modelar un paisaje físico antes y después del siglo XVI que en gran parte es producto de los cambios climáticos registrados en la región. En este sentido, fuentes históricas documentan un período seco en el Noroeste argentino desde la llegada de los españoles (1580 d.C.) hasta 1641 d.C. y un período húmedo marcado entre 1663 y 1710 d.C. (Prieto et al. 1998; Prieto y Herrera 2009). Dichos cambios también fueron registrados en los lagos de la región cordillerana, al oeste y norte de área de estudio, por Valero-Garcés et al. (2003, 2011). Estos autores relacionan los altos niveles de los lagos debido al aumento de humedad registrado a partir del siglo XVII (1650-1900 d.C.) con la Pequeña Edad de Hielo (Valero-Garcés et al. 2003, 2011). 
Sin embargo, debido a cierta variabilidad local registrada en el noroeste (Valero-Garcés et al. 2003), los efectos de este evento climático deben ser analizado en detalle en el valle de Fiambalá.

Al estado de las investigaciones sostenemos que las sociedades del primer milenio fueron las menos impactadas por los cambios ambientales que habían comenzado a ocurrir en los primeros siglos de la era cristiana, en gran parte como consecuencia de los procesos de desertificación, dado que interactuaron con bosques nativos de algarrobo y mayor acceso al agua. Probablemente, a medida que pasaba el tiempo se agudizaba la incisión de los cauces, pero aún era posible el acceso al agua para regadío de los campos. Sin embargo, este equilibrio inestable fue totalmente alterado por la conquista española, ya que provocó un nuevo despoblamiento de estas tierras por el traslado de las poblaciones según los intereses de los encomenderos (Williams y Schaposchnik 1999; Ratto y Boixadós 2012). Así, tanto los procesos naturales como culturales se combinaron para generar una mayor disponibilidad de material no consolidado que fue transportado por el viento y así no solo favorecieron los procesos de desertificación imperantes en la actualidad, sino que afectaron significativamente los sitios arqueológicos de momentos de las sociedades del primer milenio y los campos agrícolas. Al respecto, Sempé (1976) registró esos procesos deflacionarios a fines de la década de 1960 y resaltó la mala preservación de los sitios ubicados en el sector más distal del abanico del Apocango. Además, la investigadora registró la presencia de fogones superficiales (a $5 \mathrm{~cm}$ de profundidad) que evidencian los intensos procesos de agradación acaecidos en el valle. Situaciones semejantes de deterioro, por procesos de deflación, agradación y/o acreción, se observan en otros sitios arqueológicos localizados en el bolsón de Fiambalá como la aldea de Palo Blanco, Batungasta, Tatón, entre otros (Ratto et al. 2013, 2019b). De las observaciones de Sempé $(1976,1984)$ a la actualidad han pasado más de 50 años, en los cuales los procesos continuaron y la preservación e integridad de los sitios empeoró.

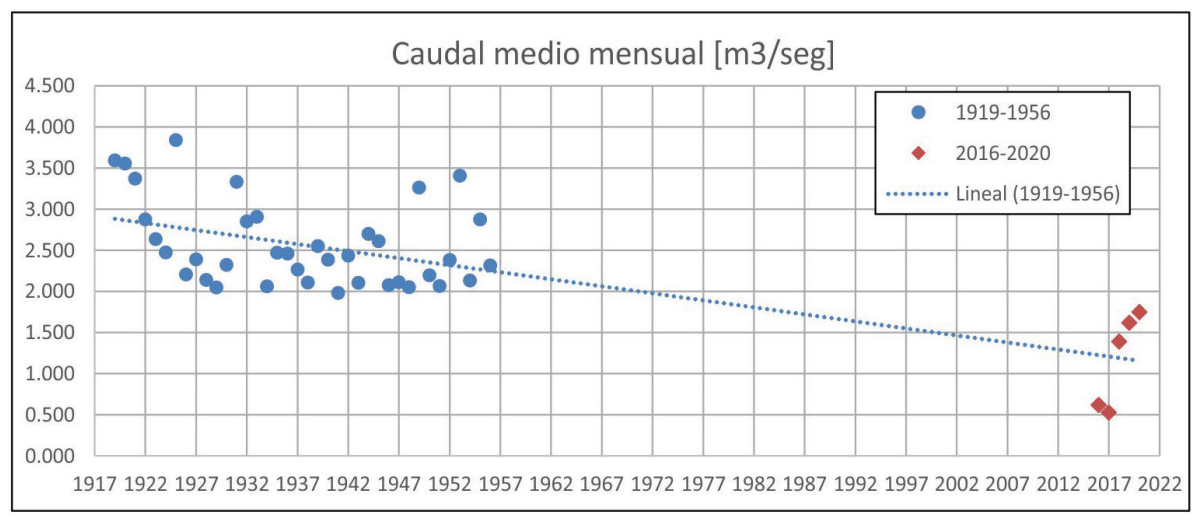

Figura 8. Gráfico del caudal medio anual del río Abaucán de acuerdo con los datos históricos provistos por el Servicio Hídrico Nacional

\section{PALABRAS FINALES}

La descripción del paisaje físico presente hoy en día en el zanjón de Apocango y sus alrededores evidencia condiciones áridas a semiáridas donde el agente eólico es uno de los principales modeladores del paisaje físico junto con el fluvio-aluvial. Estos provocaron la incisión del cauce principal del río Apocango, con mayor profundidad en el sector proximal con respecto a la distal donde se localizan los sitios arqueológicos (figura 4b-c). Estas incisiones se suman a otras previamente registradas en otros sectores del valle y del área de estudio, por lo que podemos plantear 
que fue un proceso de alcance regional que se fue dando gradualmente en tiempos prehispánicos, pero se potenciaron luego de la conquista española (Valero-Garcés y Ratto 2005; Valero-Garcés et al. 2011). Por lo expuesto, este trabajo es un claro ejemplo de la necesidad de analizar las modificaciones del paisaje físico desde distintas miradas de las disciplinas científicas, para poder entender mejor la interacción entre los medios físicos naturales y culturales y como generan cambios dinámicos a lo largo del tiempo. La articulación de las distintas líneas de evidencia nos permite sostener que los cambios en la dinámica fluvial produjeron no solo una disminución del caudal de los ríos, sino también dificultades para el acceso al agua necesaria para irrigar los campos de cultivo, lo cual dificultó la ocupación permanente de los sitios. A su vez, esto también potenció los procesos erosivos, principalmente por el agente viento, debido a la mayor disponibilidad de sedimentos dentro de los campos de cultivo abandonados. Lo expuesto en este trabajo muestra el claro impacto ambiental reciente en toda el área del zanjón de Apocango e impulsa a avanzar en el conocimiento de los impactos ambientales preconquista y periconquista, para lo cual debemos profundizar los estudios y las dataciones.

\section{AGRADECIMIENTO}

Este trabajo fue realizado en el marco del Proyecto UBACyT ID 2018 Mod I 20620170100007BA y PICT 2019-01723 (PC). Las autoras agradecen a Luis Coll por el tratamiento digital de las imágenes georreferenciadas obtenidas con Phantom 4 Pro v2 para obtener el ortomosaico y el modelo de elevación digital (DEM) con el software Agisoft (versión de prueba). Agradecen las revisiones realizadas por dos evaluadores anónimos que ayudaron a mejorar el manuscrito.

\section{REFERENCIAS BIBLIOGRÁFICAS}

Andreoni, D., B. Marconetto, V. Mors y N. Ratto (2018). Selección y manejo de recursos forestales en la región de Fiambalá (departamento Tinogasta, Catamarca). Estudios Atacameños 57:7:24.

Argerich, F. R. (2003a). Historia Económica de Catamarca. Desde la era lítica hasta el presente. Catamarca, Imprenta Quirna.

Argerich, F. R. (2003b). Crónicas históricas de la agricultura, explotaciónforestal y ganadería de Catamarca, siglo XIX y primera mitad del XX, San Fernando del Valle de Catamarca, Edicosa.

Bazán, A. R. (1996). Historia de la Catamarca. Buenos Aires, Plus Ultra.

Bruniard, E. (1982). La diagonal árida Argentina: un límite climático real. Revista Geográfica 95: 5-20.

Castañeda, E. y N. Ratto (2009). Analysis of some meteorological variables recorded at $4000 \mathrm{~m}$ in the Argentinian Subtropical Andean Region. Revista Atmósfera 22 (3): 253-264.

Costa, J. E. (1988). Rheologic, geomorphic, and sedimentologic differentiation of water floods, hyperconcentrated flows and debris flows. En: V. R. Baker, R. C. Kochel y P. C. Patton (eds.), Flood Geomorphology: 113-22. New York, Wiley.

Cuello, E. (1992). Historia de Saujil, Medanito, Palo Blanco y otros pueblos. Concejo Deliberante de la Ciudad de San Fernando del Valle de Catamarca. Catamarca. 
PATRICIA L. CiCCIOLI Y OTROS - MiRADAS INTERDISCIPLINARIAS SOBRE LOS PROCESOS AMBIENTALES ACTUANTES ...

Deri, M. N. y P.L Ciccioli (2018). Sedimentología del campo de dunas intermontano de Medanitos, Bolsón de Fiambalá, Catamarca. Revista de la Asociación Geológica Argentina 75 (3): 325-345.

Fernandez Molina, D. (2020). Sedimentología del Zanjón de Apocango, Bolsón de Fiambalá, Catamarca. Trabajo Final de Licenciatura inédito. Facultad de Ciencias Exactas y Naturales, Universidad de Buenos Aires.

Fernández-Turiel, J. L., F. J. Pérez-Torrado; A. Rodríguez-González; J. Saavedra; J. C. Carracedo; M. Rejas; A. Lobo; M. Osterrieth; J. I. Carrizo; G. Esteban; J. Gallardo y N. Ratto (2019). The large eruption 4.2 ka BP in Cerro Blanco, Central Volcanic Zone, Andes: Insights to the Holocene eruptive deposits in the southern Puna and adjacent regions. Estudios Geológicos 75(1):1-31.

Ferreira, L. (2005). Proyecto de microfilmación de la Colección de Folklore de 1921. En A. Morán, B. Bozzini y E. Solimano (comp.), Seminario Dilemas de la Biblioteca Actual. La Creatividad frente a la Crisis: 109-120. Buenos Aires, INAP.

Garleff, K., H. Singl y H. Veit (1992). New dates on the late Quaternary history of landscape and climate in the Bolsón of Fiambalá, Argentina (province Catamarca). Zentralblatt für Geologie und Paläontologie 1:333-341.

Grana, L., P. Tchilinguirian, D. E. Olivera, C. Laprida y N. I. Maidana (2016). Síntesis paleoambiental en Antofagasta de la Sierra: heterogeneidad ambiental y ocupaciones humanas en los últimos 7200 años cal AP. Intersecciones en Antropología 4: 19-32.

Garreaud, R. D., M. Vuille, R. Compagnucci y J. Marengo (2009). Present-day South American climate. Palaeogeography, Palaeoclimatology, Palaeoecology 281 (3), 180-195.

Hogg, A., T. Heaton, Q. Hua, J. Palmer, C. Turney, J. Southon, A. Bayliss, P. Blackwell, G. Boswijk, C. Bronk Ramsey, F. Petchey, P. Reimer, R. Reimer y L. Wacker (2020). SHCal20 Southern Hemisphere calibration, 0-55,000 years cal BP. Radiocarbon 62.

Morales M., S. Bustos, B. Oxman, M. Pirola, P. Tchilinguirian, M. J. Orgueira y H. Yacobaccio (2018). Exploring habitat diversity of mid-holocene hunter-gatherers in the South-Central Andes: Multi-proxy analysis of Cruces Core 1 (TC1), Dry Puna of Jujuy, Argentina. Journal of Archaeological Science: Reports 18:708-721.

Orgaz, M., A. Feely, y N. Ratto (2007). La cerámica como expresión de los aspectos sociopolíticos, económicos y rituales de la ocupación Inka en la puna de Chaschuil y el valle de Fiambalá (departamento Tinogasta, Catamarca, Argentina). En A. Nielsen, M. C. Rivolta, V. Seldes, M. Vázquez, y P. Mercolli (comps.), Procesos sociales Prehispánicos en el Sur Andino. La vivienda, la comunidad y el territorio, Tomo 1: 239-250. Córdoba, Editorial Brujas.

Orgaz, M. y N. Ratto (2015). Estrategias de ocupación incaica en el sur del Noroeste Argentino (Departamento Tinogasta, Catamarca): la apropiación de paisajes sagrados y la memoria social. Revista Nawpa Pacha. Journal of Andean Archaeology 35 (2):217-235.

Orgaz M., N. Ratto y L. Coll (2014). Aportes para la construcción de los paisajes agrícolas en la región de Fiambalá, Tinogasta, Catamarca: nuevas evidencias. Relaciones XXXIX (1): 79-94.

Prieto, M. R. y R. Herrera (2009). Documentary sources from South America: Potential for climate reconstruction. Palaeogeography, Palaeoclimatology, Palaeoecology 281: 196-209.

Prieto, M. R., R. Herrera y P. Dussel (1998). Clima y disponibilidad hídrica en el sur de Bolivia y noroeste de Argentina entre 1560 y 1710. Los documentos españoles como fuente de datos ambientales. Bamberger Geographische Schriften 15: 35-56.

Ratto, N. (2013). A modo de introducción: la articulación de estudios arqueológicos, paleoambientales e 
históricos en el oeste tinogasteño (Catamarca). En: N. Ratto (comp.), Delineando prácticas de la gente del pasado: Los procesos sociohistóricos del oeste catamarqueño:17-44. Buenos Aires, Sociedad Argentina de Antropología.

Ratto, N. y M, Basile (2020). Articulando saberes: el aporte de las colecciones particulares a los proyectos de investigación. Revista del Museo de La Plata 5(1): 234-245.

Ratto, N., M. Basile y A. Feely (2012). Rutas y espacios conectados: las tierras altas y bajas del oeste tinogasteño ca. 2000-1000 A.P. (Catamarca). Revista de Antropología Chilena 26 (2):33-58.

Ratto, N. y R. Boixadós (2012). Arqueología y Etnohistoria. La construcción de un problema de investigación (Abaucán, Tinogasta, Catamarca). Memoria Americana 20 (2): 187-220.

Ratto, N., N. Bonomo y A. Osella (2019a). Arquitectura de la aldea de Palo Blanco (ca. 0-1000 d,C,), departamento de Tinogasta, Catamarca, Argentina. Latin American Antiquity 30(4):760-779.

Ratto, N., M. C. Montero, F. Hongn y B. Valero Garcés (2013). La historia ambiental de las sociedades productivas del oeste tinogasteño (Catamarca), siglos I a XVI. En N. Ratto (comp.), Delineando prácticas de la gente del pasado: Los procesos sociohistóricos del oeste catamarqueño:45-66. Buenos Aires, Sociedad Argentina de Antropología.

Ratto, N., M. Orgaz, L. Coll y A. Feely (2019b). Vulcanismo regional y su impacto en el bolsón de Fiambalá (departamento Tinogasta, Catamarca): El caso del sitio Cardoso. Relaciones XLIV (2): 321-329.

Reindel, M. y J. Isla (2013). Cambio climático y patrones de asentamiento en la vertiente occidental de los Andes del sur del Perú. Diálogo Andino 41: 83-99.

Rojas, F. (2013). Rol de la minería y el ferrocarril en el desmonte del oeste riojano y catamarqueño (Argentina) en el período 1851-1942. Población y Sociedad 20 (2): 99-123.

Rojas, F., M. R, Prieto, P. Villagra y J. Álvarez (2014). Deforestación y actividades productivas en los Valles del oeste de La Rioja y Catamarca, desde mediados del siglo XIX hasta la actualidad. Boletín de Estudios Geográficos 103: 19-57.

Rubiolo, R., L. Martínez y F. Pereyra (2003). Hoja Geológica 2769- IV Fiambalá, Provincias de Catamarca. Boletín 421: 77. Buenos Aires, Servicio Geológico Minero Argentino.

Sempé, M. C. (1976). Contribución a la arqueología del valle de Abaucán. Tesis doctoral inédita. Facultad de Ciencias Naturales y Museo. Universidad Nacional de La Plata, La Plata.

Sempé, M. C. (1984). Mishma N7. Sitio incaico del valle de Abaucán. Dpto. Tinogasta, Pcia. Catamarca. Revista del Museo de La Plata. Antropología N.S. VIII (65): 405-438.

Servicio Nacional de Información Hídrica (2021). Datos históricos de caudal medio mensual (1919-1956 y 2017-2020) y caudal mensual máximo (1940-1953 y 2016-2019) Abaucán 201- Tinogasta. https://snih. hidricosargentina.gob.ar/

Servicio Meteorológico Nacional (2015). Información climatológica de la localidad de Tinogasta (Catamarca), para el período $1985-2015$.

Turner J. C. (1967). Descripción Geológica de la Hoja 13 b, Chaschuil. Provincias de Catamarca y La Rioja. Boletín 106. Buenos Aires, Servicio Nacional Minero Geológico.

Valero-Garcés, B., A. Delgado, A. Navas, L. Edwards, A. Schwalb y N. Ratto (2003). Patterns of regional 
hydrological variability in central-southern Altiplano $\left(18^{\circ}-26^{\circ} \mathrm{S}\right)$ lakes during the last 500 years. Palaeogeography, Palaeoclimatology, Palaeoecology 194 (1-3): 319-338.

Valero Garcés, B. y N. Ratto (2005). Registros Lacustres Holocénicos en la Puna de Chaschuil y el Bolsón de Fiambalá (Dpto. Tinogasta, Catamarca): Resultados Preliminares. Simposio Geología del Cuaternario, Paleontología, Geoarqueología, Paleoclimas y Paleoambientes (Coord. J. Rabassa). En: Actas del XVI Congreso Geológico Argentino, T ${ }^{\circ}$ IV, pp. 163-170. La Plata.

Valero-Garcés, B., N. Ratto, A. Moreno, A. Navas y A. Delgado-Huertas (2011). Los Lagos del Altiplano de Atacama y el Noroeste Argentino como sensores de cambios hidrológicos durante el Holoceno. En M. Caballero y B. Ortega Guerrero (eds.), Escenarios de Cambio climático: Registros del Cuaternario en América Latina: 185-208. D.F. México, Editado por UMEC-UNAM.

Vervoorst, F. (1951). Resultados de un viaje a la cuenca de Laguna Verde (Tinogasta, Catamarca). Actas de la XV Semana de Geografía: 61-67. Buenos Aires, Sociedad Argentina de Estudios Geográficos.

Viera, V.O. (1982). Geomorfología (control de médanos). Área: Fiambalá (Provincia de Catamarca). Proyecto NOA Hídrico segunda fase.

Williams, V. y A. Schaposchnik (1999). Estructuras étnicas en el Oeste de Catamarca (Argentina) entre 1414 y 1642 AD. En: Especial de Etnohistoria (Publicación electrónica). Buenos Aires, NAYA. 
